COMmENTARY ON COVID-19 AND THE FoOd SyStem

\title{
The impact of COVID-19 on food security and income of women farmers in South and Southeast Asia
}

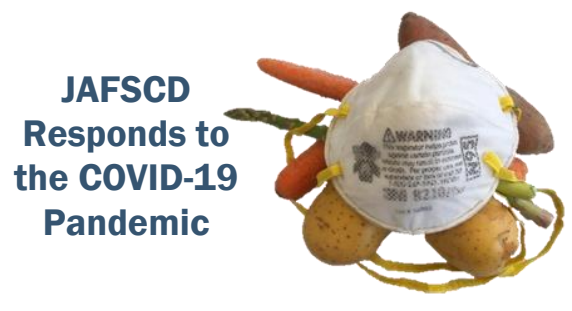

Neha ${ }^{a}$ and Kaustubh Kumar ${ }^{b *}$

Solidaridad Network Asia

Submitted October 28, 2020 / Published online February 7, 2021

Citation: Neha, \& Kumar, K. (2021). The impact of COVID-19 on food security and income

of women farmers in South and Southeast Asia. Journal of Agriculture, Food Systems, and

Community Development, 10(2), 269-271. https://doi.org/10.5304/jafscd.2021.102.013

Copyright (C) 2021 by the Authors. Published by the Lyson Center for Civic Agriculture and Food Systems. Open access under CC-BY license.

\section{Abstract}

The COVID-19 pandemic has disrupted and adversely affected all sectors of the economy and society. This essay provides an overview of the impact of the pandemic (and associated lockdowns) on the food security and income of women farmers in South and Southeast Asia. It also lists the coping strategies applied by them to reduce the impact.

\section{Keywords}

COVID-19, Pandemic, Women Farmers, Food Security, Income, Asia

\footnotetext{
a * Neha, Assistant Manager (Gender, Planning, Monitoring, and Evaluation), Solidaridad Network Asia; neha@solidaridadnetwork.org

$\mathrm{b} *$ Corresponding author: Kaustubh Kumar, Assistant Manager (Planning, Monitoring, and Evaluation), Institutional affiliation: Solidaridad Network Asia; A-5, 1st Floor, Shankar Garden, Main Najafgarh Road, Vikas Puri; New Delhi- 110018, India; +91 9911019079; kaustubh.kumar@solidaridadnetwork.org
}

\section{Author Note}

Both authors contributed equally to the essay. 
"Everything is challenging with this pandemic and the quarantine. It was already challenging for us and is even more difficult now. Our household income dropped drastically, no one wants to buy raw rubber anymore now, so my husband had stopped tapping. I have a small kiosk selling daily staple, but even that also has less customer now. We are relying for our daily needs on these vegetable crops we grow around the house"- Siti Aisah, Indonesia.

$\mathrm{T}$ he impact of the coronavirus pandemic throughout 2020 was very disruptive. By the end of September 2020, more than 30 million COVID-19 cases had been reported and more than one million people had died globally. ${ }^{1}$ The pandemic has strained supply chains, prevented agricultural activity, affected the sustainability of food systems, and caused economic slowdowns.

Women, in particular, have faced the worst of the impact of COVID-19. Tandra Biswas from Bangladesh, who depends on dairy farming, saw her income decrease by half. She said, "I was near to stopping my elder daughter's education as [the] price of milk drastically declined due to [the] pandemic and it hit [the] family income." Tandra Biswas reflects the emotions of the many women who depend on single source of income that has been affected by the pandemic. Farming depends significantly on the timely availability and cost of inputs, availability of labor, and the presence of a market for the products. A rapid assessment conducted by Solidaridad in July 2020 highlighted the plight of women who were left vulnerable due to a lack of access to technology, financial credits, input supplies, and markets. ${ }^{2}$ Women who had planted crops prior to the COVID-19 pandemic found themselves stranded without labor to harvest the crops: "I have started vegetable cultivation on my own along with household chores as this pandemic has disrupted [the] mobility of migrant workers," said Nomita Rani Biswas, one of the better-off women farmers in Bangladesh.

More than one-third of the women interviewed by Solidaridad reported reduced income, which they attributed to the decrease in agricultural and off-farm work. Ms. Karuppaiya from Sri Lanka had to resort to selling vegetables to keep her children fed: "My husband lost his job on April 1 due to COVID19. Our income [is] reduced and it is a hard time paying for food for adults and children. I managed to sell some vegetables to cover the household expenses. Meanwhile, [I'm] looking forward to start up a household business to increase the income within a month."

Income has been a key driver in ensuring food security. The study found that due to their reduced incomes, half the women interviewed in Bangladesh and more than two-thirds of the women interviewed in India, Sri Lanka, and Indonesia have not been able to afford three meals a day. The major reasons cited are loss of income in the family and/or household, loss of cash to buy food, and lack of accessibility to food items due to market closure and movement restrictions. "COVID-19 has made it hard to afford food for the adults and children in my household. My husband lost [his] job abroad, so we had to move to my mother's house to feed the children," said Sundaram Balakumari from Sri Lanka.

Food security cannot be looked at separately from access to drinking water. Respondents in India $(12 \%)$ and Sri Lanka $(18 \%)$ found it difficult to ensure sufficient drinking water for themselves and their household during lockdown. None of the respondents in Bangladesh or Indonesia reported water insecurity (see Figure 1), likely because the respondents are located in the water-rich delta areas of these two countries. The adverse effects of reduced access to safe drinking water reported by them include dehydration, weakness, a loss of overall health, an increase in expenditures on health care, and an increase in household vulnerability.

1 https://www.worldometers.info/coronavirus/

2 The rapid assessment conducted in Bangladesh, India, and Sri Lanka in South Asia, and Indonesia in Southeast Asia 
While the pandemic has caused a lot of suffering and distress for women farmers, we can also see them fighting through the difficulties and finding out solutions to mitigate their problems. To make up for the income loss, Moyna Begum from Bangladesh made 750 cloth masks and sold them in the community. Similarly, Tandra Biswas started to do aquaculture (along with dairy production) to compensate for the loss of income due to the reduced price of milk. Similarly, Listiani from Indonesia started growing vegetables with help from her husband (who had lost his job due to COVID-19) to sell in the nearby market. Further steps for alleviating the adverse impacts of COVID-19 on food systems through a gendered lens may include a strong role for public agencies in increasing access to safe and nutritious food and water through public distribution, cash transfers to women's bank accounts, the promotion of collective-based livelihood activities for women, priority health centers for women, and intensive digital outreach targeted at women in their local language.

Solidaridad Asia has been at the forefront of making economies that work for the poor and are inclusive and in balance with nature. Over the last decade, the Asia office of the Solidaridad Network has worked on different commodity supply chains to make them inclusive and sustainable. By reaching out to 500,000 farmers with information and training, we have brought nearly 700,000 hectares (1.7 million acres) of land under sustainable management. During the pandemic, in addition to providing relief support, Solidaridad Asia has also reached out to its program beneficiaries in different countries to understand the effect of the pandemic at various levels in the supply chain in order to come up with long-term strategies for mitigating the impact of the pandemic.

Apart from being a health crisis, this pandemic is a food security and economic crisis. The lockdown aimed at containing the pandemic, however, has had interlinked and far-reaching adverse ramifications for women farmers, through multiple pathways including the triad of agri-market-income shock and reduced access to food and water. A sustained effort in ameliorating these issues is greatly needed at this time.

\section{Acknowledgements}

We are grateful to Dr. Shatadru Chattopadhayay, Managing Director, Solidaridad Asia, and Nitin Rao, Regional Lead (Planning, Monitoring, and Evaluation), Solidaridad Asia for their guidance and helpful comments on an earlier version of the manuscript. 